\title{
Article \\ Isorhamnetin Ameliorates Dry Eye Disease via CFTR Activation in Mice
}

\author{
Ho K. Lee ${ }^{1,2}$, Jinhong Park ${ }^{1}$, Bo-Rahm Kim ${ }^{3}$, Ikhyun Jun ${ }^{3}{ }^{-1}$, Tae-im Kim ${ }^{3}$ and Wan Namkung ${ }^{1,2, *}$ \\ 1 College of Pharmacy and Yonsei Institute of Pharmaceutical Sciences, Yonsei University, 85 Songdogwahak-ro, \\ Yeonsu-gu, Incheon 21983, Korea; jason.hoking@gmail.com (H.K.L.); jjinung@yonsei.ac.kr (J.P.) \\ 2 Interdisciplinary Program of Integrated OMICS for Biomedical Science Graduate School, Yonsei University, \\ Seoul 03722, Korea \\ 3 Department of Ophthalmology, College of Medicine, Yonsei University, 50 Yonsei-ro, Seodaemoon-Gu, \\ Seoul 03722, Korea; cjlovem@naver.com (B.-R.K.); HADESDUAL@yuhs.ac (I.J.); TIKIM@yuhs.ac (T.-i.K.) \\ * Correspondence: wnamkung@yonsei.ac.kr
}

Citation: Lee, H.K.; Park, J.; Kim, B.-R.; Jun, I.; Kim, T.-i.; Namkung, W. Isorhamnetin Ameliorates Dry Eye Disease via CFTR Activation in Mice. Int. J. Mol. Sci. 2021, 22, 3954 https://doi.org/10.3390/ijms22083954

Academic Editor: Claudio Bucolo

Received: 2 March 2021

Accepted: 9 April 2021

Published: 12 April 2021

Publisher's Note: MDPI stays neutral with regard to jurisdictional claims in published maps and institutional affiliations.

Copyright: (c) 2021 by the authors. Licensee MDPI, Basel, Switzerland. This article is an open access article distributed under the terms and conditions of the Creative Commons Attribution (CC BY) license (https:/ / creativecommons.org/licenses/by/ $4.0 /)$.

\begin{abstract}
Dry eye disease is one of the most common diseases, with increasing prevalence in many countries, but treatment options are limited. Cystic fibrosis transmembrane conductance regulator (CFTR) is a major ion channel that facilitates fluid secretion in ocular surface epithelium and is a potential target of therapeutic agent for the treatment of dry eye disease. In this study, we performed a cell-based, high-throughput screening for the identification of novel natural products that activate CFTR and restore the aqueous deficiency in dry eye. Screening of 1000 natural products revealed isorhamnetin, a flavonol aglycone, as a novel CFTR activator. Electrophysiological studies showed that isorhamnetin significantly increased CFTR chloride current, both wild type and $\triangle$ F508-CFTR. Isorhamnetin did not alter intracellular cAMP levels and the activity of other ion channels, including ANO1, ENaC, and hERG. Notably, application of isorhamnetin on mouse ocular surface induced CFTR activation and increased tear volume. In addition, isorhamnetin significantly reduced ocular surface damage and expression of interleukin (IL)- $1 \beta$, IL- 8 , and tumor necrosis factor (TNF)- $\alpha$ in an experimental mouse model of dry eye. These data suggest that isorhamnetin may be used to treat dry eye disease.
\end{abstract}

Keywords: isorhamnetin; cystic fibrosis transmembrane conductance regulator; dry eye

\section{Introduction}

Dry eye disease is a common ocular disease with a broad group of ocular conditions that are caused by inadequate production of tears and excessive tear evaporation, resulting in lack of ocular lubrication [1]. Dry eye disease is characterized by symptoms of dryness, pressure behind the eye, and other inflammation-related symptoms that affect quality of life [2,3]. Approximately $5 \sim 54.3 \%$ of the population suffers from the disease, making it one of the most prevalent diseases in the world [4]. Recent studies on dry eye disease have shown that inflammation of the lacrimal gland, meibomian gland, cornea, and conjunctiva plays an important role in its pathogenesis, with a marked increase in tear inflammatory cytokines and immune cell infiltration [5].

Currently available treatments for the dry eye disease include artificial eye drops, which can moisten the eyes for a short period of time upon treatment before it evaporates, and cyclosporine, which is used to subdue inflammation [6,7]. However, these treatments only give temporary relief by indirectly suppressing symptoms, and there are no treatments available that can last longer while moisturizing the eye. Recently, $\mathrm{P}_{2} \mathrm{Y}_{2}$ receptor agonists, such as diquafosol, which could restore the tear film stability by transiently increasing water secretion from calcium-activated chloride channels expressed on the conjunctival epithelium, have been suggested as a possible treatment for the disease [8]. Various ion channels including cystic fibrosis transmembrane conductance regulator (CFTR), anoctamin 
1(ANO1), and ENaC have been identified in the conjunctival epithelium, which produces mucin and tear, and the ion channels play pivotal roles in the regulation of tear film homeostasis [9-11]. CFTR is a cAMP-regulated chloride channel expressed in various epithelia including airway, intestinal, and ocular epithelia. Mutations in CFTR, which impair its expression and function, cause cystic fibrosis (CF), the most common lethal genetic disease, and CF patients showed that they exhibit ocular surface abnormality of low tear film stability [12].

Recent studies showed that forskolin-induced activation of CFTR was detected in mouse, rat, rabbit, and human ocular epithelium and revealed CFTR is a promising target for a new therapeutic agent for the treatment of dry eye disease [11]. In human ocular surface, increasing the fluid transport via CFTR activators can induce sustained flow of water compared to the transient activation of calcium-activated chloride channels with the $\mathrm{P}_{2} \mathrm{Y}_{2}$ agonist [13], and these results strongly suggest that CFTR activators are potential agents for the treatment of dry eye. The fluid secretion from the ocular epithelia could restore the impaired aqueous tear film layer of the dry eye patients. In this study, we identified a novel CFTR activator, isorhamnetin, and investigated the effectiveness of isorhamnetin in an experimental mouse model of dry eye.

\section{Results}

\subsection{Identification of CFTR Activator}

A cell-based screening of 1000 natural products was performed for the identification of novel CFTR activators. The effect of the natural products on CFTR activity was measured with YFP quenching assay in CHO-K1 cells stably expressing human CFTR and a halide sensor YFP-F46L/H148Q/I152L. The screening revealed isorhamnetin, which significantly increased CFTR chloride channel activity in a dose-dependent manner (Figure 1A,B). Apical membrane currents were measured to verify the effect of isorhamnetin on CFTR chloride channel activity in WT-CFTR expressing FRT cells. Isorhamnetin fully activated CFTR at $30 \mu \mathrm{M}$ with $\mathrm{EC}_{50}$ of $6.6 \pm 1.1 \mu \mathrm{M}$, and CFTR chloride current was not further increased by $20 \mu \mathrm{M}$ forskolin, inducing maximal activation of CFTR (Figure 1C,D).

\subsection{Characterization of Isorhamnetin}

To investigate the effect of isorhamnetin on the intracellular cAMP signaling, which induces CFTR activation, cAMP concentration changes by forskolin, an adenylyl cyclase activator, and isorhamnetin were observed in FRT cells. Isorhamnetin did not alter the intracellular cAMP levels (Figure 2A). In previous study, the effects of a small-molecule CFTR activator on other ion channels affecting tear homeostasis were investigated [14]. So, we observed the effect of isorhamnetin on ANO1 and $\mathrm{ENaC}$ channels expressing in ocular epithelium. Apical membrane current of ANO1 was measured in FRT cells expressing human $\mathrm{ANO1}$, and $\mathrm{ENaC}$ short-circuit current was measured in T84 cells expressing ENaC. Isorhamnetin did not alter $\mathrm{ANO} 1$ and $\mathrm{ENaC}$ function (Figure $2 \mathrm{~B}, \mathrm{C}$ ). To investigate the cardiac safety assessment of isorhamnetin, the effect of isorhamnetin on hERG potassium channel activity was observed in HEK293T cells expressing hERG by FluxOR potassium ion channel assay. Isorhamnetin did not affect hERG channel activity (Figure 2D). To determine the cytotoxic effect of isorhamnetin, cell viability was measured using MTS assay in corneal epithelial (CorE) cells and conjunctival epithelial (ConjE) cells. In both CorE and ConjE cells, isorhamnetin did not affect the cell viability at $30 \mu \mathrm{M}$ and Triton X-100 (0.01\%) markedly decreased cell viability (Figure 2E,F). 
A

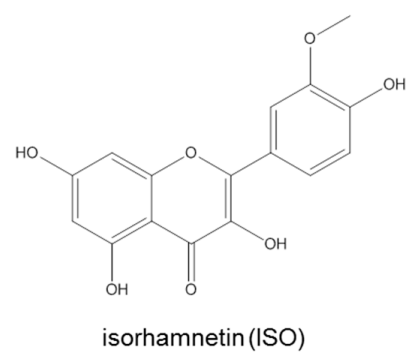

C

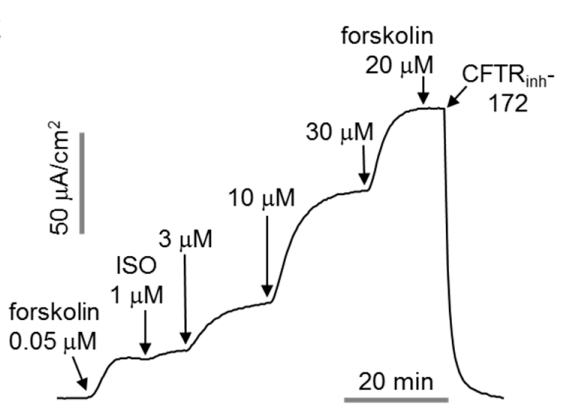

B

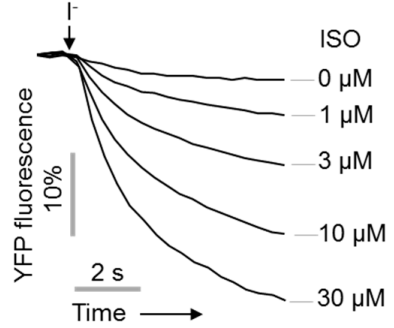

D

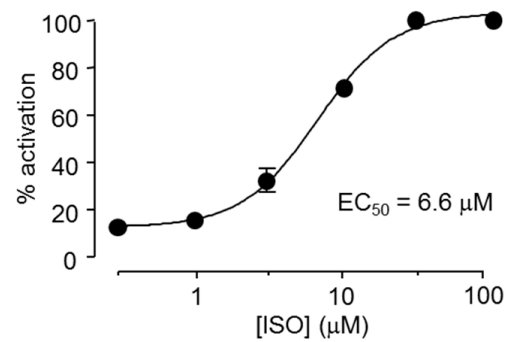

Figure 1. Identification of novel CFTR activator, isorhamnetin. (A) Chemical structure of isorhamnetin (B) YFP fluorescence measured in CHO-K1 cells expressing CFTR and YFP-F46L/H148Q/I152L. Indicated concentrations of isorhamnetin were applied 10 min prior to extracellular $\mathrm{I}^{-}$addition. (C) Apical membrane current measured in WT-CFTR expressing FRT cells. CFTR was activated by indicated concentrations of isorhamnetin and forskolin, CFTR agonist, and inhibited by $10 \mu \mathrm{M}$ $\mathrm{CFTR}_{\text {inh }}$-172. (D) Dose-response curve (mean \pm S.E., $\left.n=3-4\right)$.

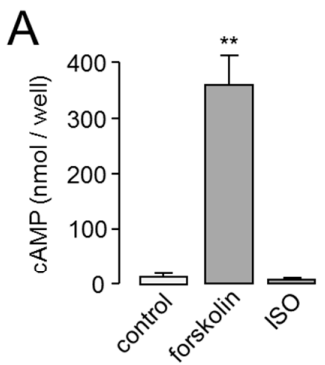

D

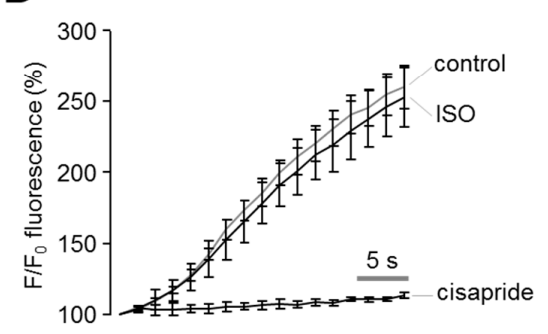

B

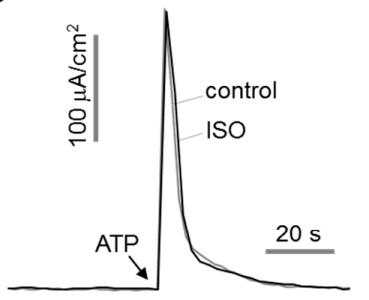

E

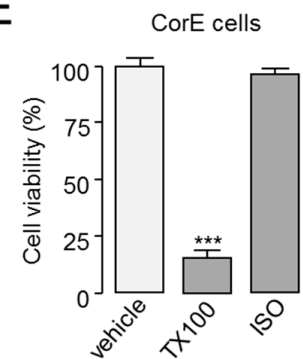

C

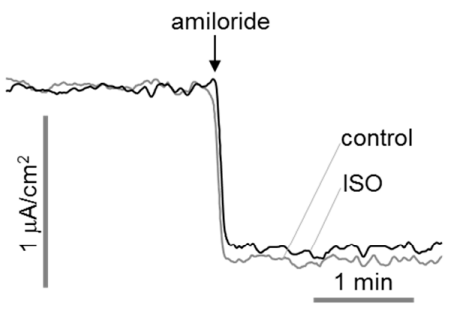

Figure 2. Characterization of isorhamnetin. (A) cAMP accumulation in FRT cells in response to addition of isorhamnetin $(30 \mu \mathrm{M})$ and forskolin $(20 \mu \mathrm{M})$ (mean \pm S.E., $n=3-4)$. (B) Apical membrane currents were measured in FRT-ANO1 cells. Isorhamnetin $30 \mu \mathrm{M}$ was added 10 min prior to ANO1 activation by $100 \mu \mathrm{M}$ ATP. (C) Effect of isorhamnetin on ENaC activity was observed in T84 cells. Isorhamnetin $30 \mu \mathrm{M}$ was applied $10 \mathrm{~min}$ prior to ENaC inhibition by $100 \mu \mathrm{M}$ amiloride. (D) Effect of isorhamnetin on hERG potassium channel activity was measured in HEK293T cells expressing hERG (mean \pm S.E., $n=3)$. Isorhamnetin $30 \mu \mathrm{M}$ was pretreated for $10 \mathrm{~min}$. The hERG channel was inhibited by $50 \mu \mathrm{M}$ cisapride. (E,F) CorE and ConjE cells were treated with isorhamnetin $(30 \mu \mathrm{M})$ for $48 \mathrm{~h}$ and cell viability was determined by MTS assay. Triton X-100 (TX100, 0.01\%) was used as a positive control (mean \pm S.E., $n=4-6$ ). ${ }^{* *} p<0.01,{ }^{* * *} p<0.001$. 


\subsection{Whole-Cell Patch Clamp in CHO-CFTR Cells}

To further characterize activation of CFTR by isorhamnetin, whole-cell recording performed on CHO-K1 cells expressing CFTR. As shown in Figure 3, application of $30 \mu \mathrm{M}$ isorhamnetin fully activated CFTR $\mathrm{Cl}^{-}$currents exhibit a linear current/voltage relationship. The isorhamnetin-induced $\mathrm{CFTR}^{-} \mathrm{Cl}^{-}$currents were almost completely blocked by CFTR $_{\text {inh }}-172$.

A

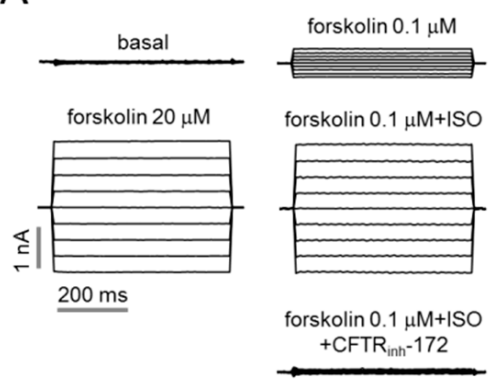

B

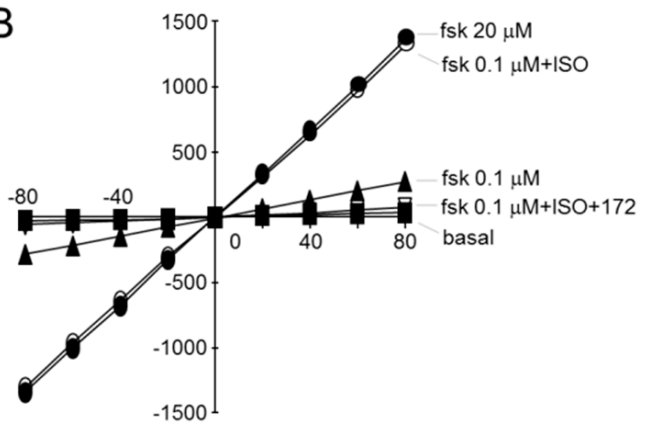

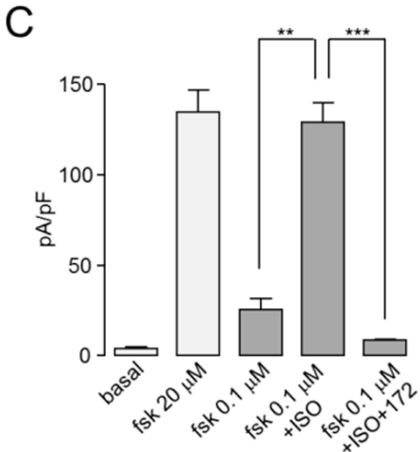

Figure 3. Isorhamnetin fully activates CFTR chloride currents. (A) Whole-cell currents were recorded at a holding potential at $0 \mathrm{mV}$, and pulsing to voltages between $\pm 80 \mathrm{mV}$ (in steps of $20 \mathrm{mV}$ ) in CHO-K1 cells expressing WT-CFTR. CFTR was activated by indicated concentrations of forskolin and isorhamnetin and inhibited by $10 \mu \mathrm{M} \mathrm{CFTR}_{\text {inh }}-172$. (B) Current/voltage plot of mean currents at the middle of each voltage pulse. (C) Summary of current density data measured at $+80 \mathrm{mV}$ (mean \pm S.E., $n=3-5) .{ }^{* *} p<0.01,{ }^{* * *} p<0.001$.

\subsection{Isorhamnetin Potentiates Low-Temperature-Rescued $\triangle F 508$-CFTR}

Patients with cystic fibrosis (CF) who have the CFTR loss of function mutation have an increased incidence of dry eye syndrome [12]. The most common mutation in CFTR in $\mathrm{CF}$ is $\triangle \mathrm{F} 508$, accounting for approximately $70 \%$ of all mutations [15]. To investigate whether isorhamnetin can enhance $\Delta$ F508-CFTR activity, we measured apical membrane currents in $\triangle$ F508-CFTR expressing FRT cells. As shown in Figure 4, isorhamnetin strongly potentiated forskolin-induced $\triangle$ F508-CFTR chloride current in a dose-dependent manner. Notably, application of $30 \mu \mathrm{M}$ isorhamnetin doubled the $\triangle \mathrm{F} 508$-CFTR chloride current activated by $20 \mu \mathrm{M}$ forskolin.

A

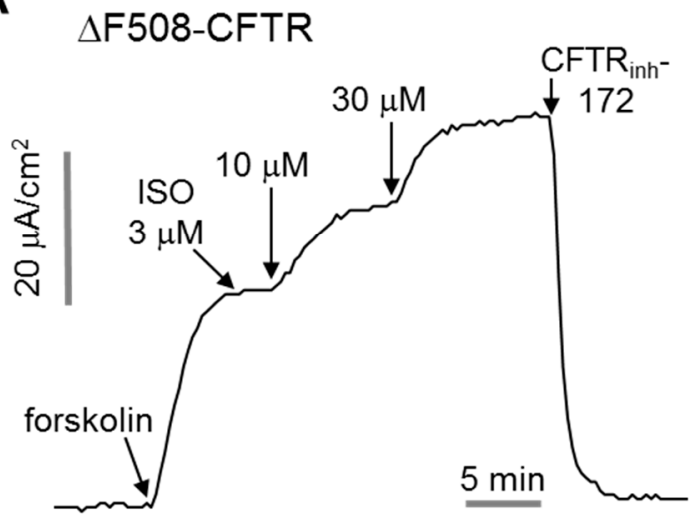

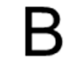

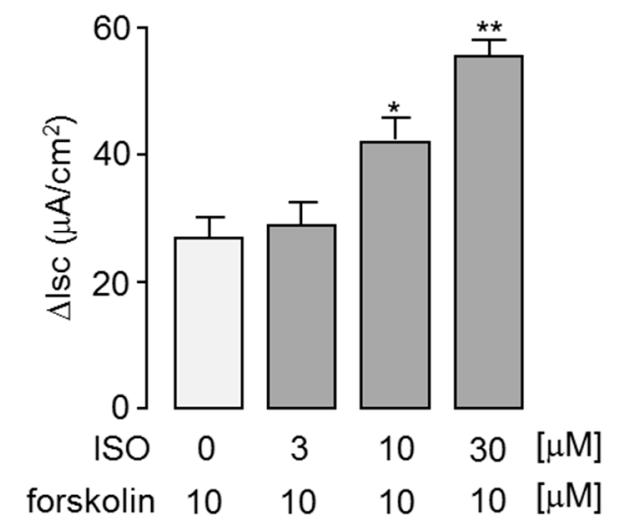

Figure 4. Isorhamnetin potentiates low-temperature-rescued $\triangle F 508$-CFTR. (A) Apical membrane current was measured in FRT cells expressing human $\triangle$ F508-CFTR. $\triangle$ F508-CFTR was rescued by low-temperature $\left(27^{\circ} \mathrm{C}\right)$ incubation for $24 \mathrm{~h}$. Where indicated, forskolin, isorhamnetin, and $\mathrm{CFTR}_{\text {inh }}-172$ were added. (B) Summary of apical membrane current increases $\left(\Delta \mathrm{Isc}_{\text {, }}\right.$ mean \pm S.E., $n=3-4) .{ }^{*} p<0.05,{ }^{* *} p<0.01$. 


\subsection{Isorhamnetin Increases Ocular Surface Chloride Secretion and Tear Volume}

To investigate whether isorhamnetin can increase ocular tear volume in mice, opencircuit ocular surface potential difference (PD) was measured in CD-1 mice. As shown in Figure $5 \mathrm{~A}-\mathrm{C}$, to increase the driving force for chloride secretion, $\mathrm{ENaC}$ was inhibited by amiloride and continuously perfused ocular surface with a solution containing low $\mathrm{Cl}$ and then CFTR was stimulated by forskolin or isorhamnetin. Isorhamnetin significantly hyperpolarized ocular PD, and the hyperpolarization was inhibited by CFTR $_{\text {inh- }}-172$. To observe the effect of isorhamnetin on tear secretion in mice, tear volume was determined using phenol red thread tear test in CD-1 mice. Interestingly, isorhamnetin tear volume was significantly increased by $30 \mu \mathrm{M}$ isorhamnetin, which induced maximal activation of CFTR in vitro, and the increased tear volume was completely suppressed by CFTR $_{\text {inh }}-172$ (Figure 5D).

A
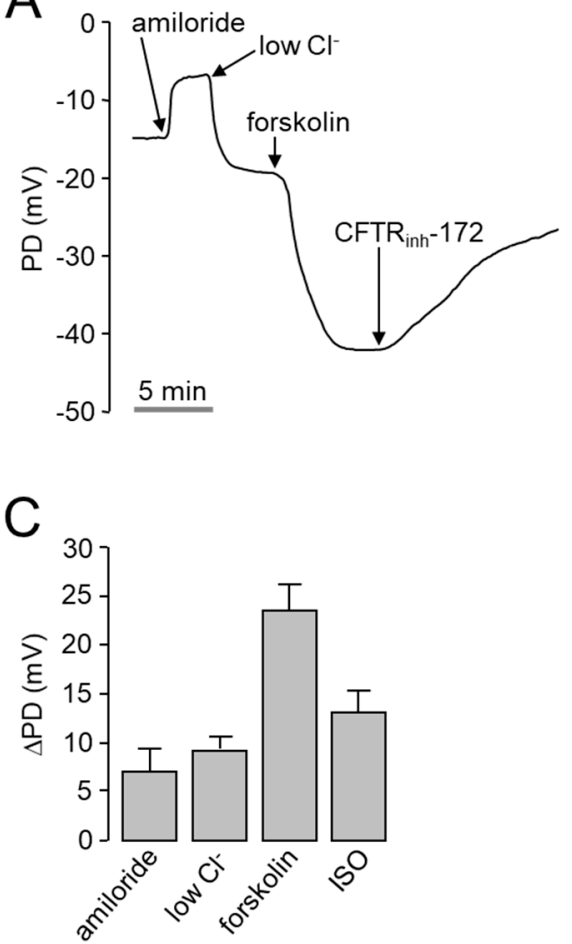

B

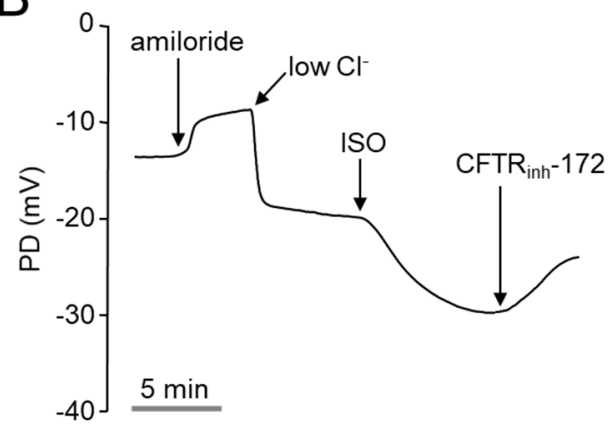

D

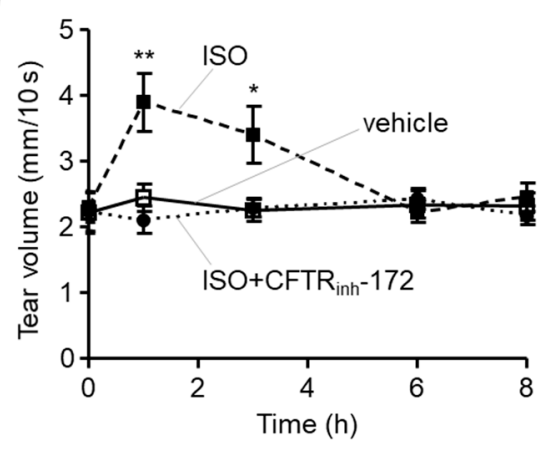

Figure 5. PD measurement and tear fluid volume measurement of isorhamnetin in live mice. (A,B) Representative continuous recordings of change in ocular surface open-circuit PD in response to perfusion with solutions containing indicated compounds (see Section 4). (C) Summary of changes in ocular surface PD $(\triangle \mathrm{PD})$. (D) Tear volume was measured at the indicated times after $2.5 \mu \mathrm{L}$ volume of single ocular delivery of vehicle, isorhamnetin $(30 \mu \mathrm{M})$, or isorhamnetin with CFTR $_{\mathrm{inh}}-172(20 \mu \mathrm{M})$ in CD-1 mice (mean \pm S.E., $n=10$ ). ${ }^{*} p<0.05,{ }^{* *} p<0.01$.

\subsection{Isorhamnetin Ameliorates Dry Eye Disease in Scopolamine-Induced Dry Eye Mouse Model}

To investigate whether isorhamnetin can ameliorate dry eye disease, we observed the effect of isorhamnetin on scopolamine-induced dry eye mouse model. To examine the efficacy of isorhamnetin on ocular injury of the mice under the dry eye model, isorhamnetin or vehicle (PBS) was administered to each eye three times a day for 10 days. As shown in Figure 6, isorhamnetin significantly reduced corneal erosion and increased tear volume in the scopolamine-induced dry eye mice. Corneal erosion and reduced tear volume were significantly restored by $30 \mu \mathrm{M}$ isorhamnetin, which induced maximal activation of CFTR in vitro (Figure 6). 
A

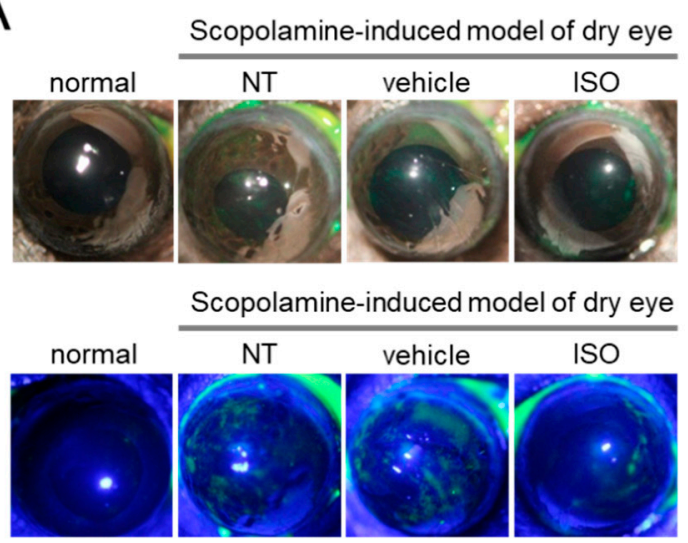

B

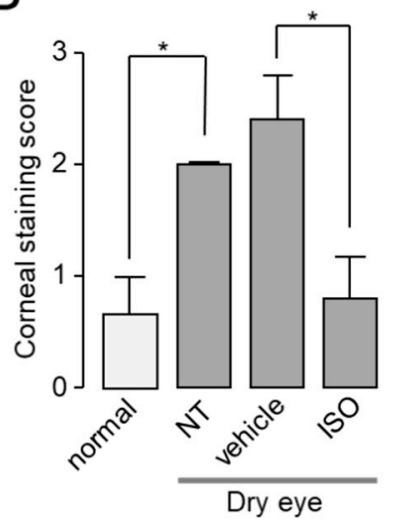

C

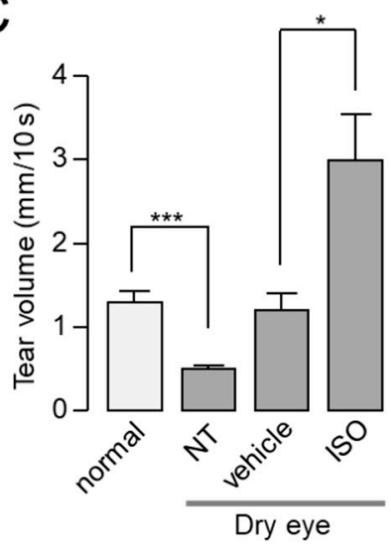

Figure 6. Isorhamnetin reduced ocular surface damage and increased tear fluid volume in a scopolamine-induced dry eye mouse model. (A) Representative photographs of mouse eyes (top) and corneal fluorescein staining images of normal and dry eye mice (bottom). Vehicle and isorhamnetin were treated three times a day for 10 days. (B) Degree of corneal epithelial disruption of each case measured by fluorescein staining on a five-point scale (mean \pm S.E., $n=5$ ). (C) Basal tear volume of each case measured with phenol red thread tear test (mean \pm S.E., $n=5$ ). NT, not treated. ${ }^{*} p<0.05,{ }^{* * *} p<0.001$.

\subsection{Isorhamnetin Reduces Ocular Pro-Inflammatory Cytokines in Dry Eye Mouse}

Previous studies have shown that mRNA expression levels of interleukin (IL)- $1 \beta$, IL-6, IL-8, tumor necrosis factor (TNF)- $\alpha$, interferon (IFN)- $\gamma$, and matrix metallopeptidase (MMP)-9 were significantly increased in tears and conjunctiva of dry eye patients compared to normal controls [16-19].

In cornea and conjunctiva of normal or dry eye model mice, the mRNA expression levels of IL-1 $\beta$, IL-6, IL-8, TNF- $\alpha$, IFN- $\gamma$, and MMP-9 were investigated by real-time PCR in the presence or absence of isorhamnetin. As shown in Figure 7, the mRNA expression levels of IL- $1 \beta$, IL- 8, TNF- $\alpha$, and IFN- $\gamma$ in cornea and conjunctiva were significantly increased compared to normal mice, but the mRNA expression levels of MMP-9 were not significantly changed. Application of isorhamnetin strongly reduced the increased mRNA expression of cytokines in dry eye mice. 

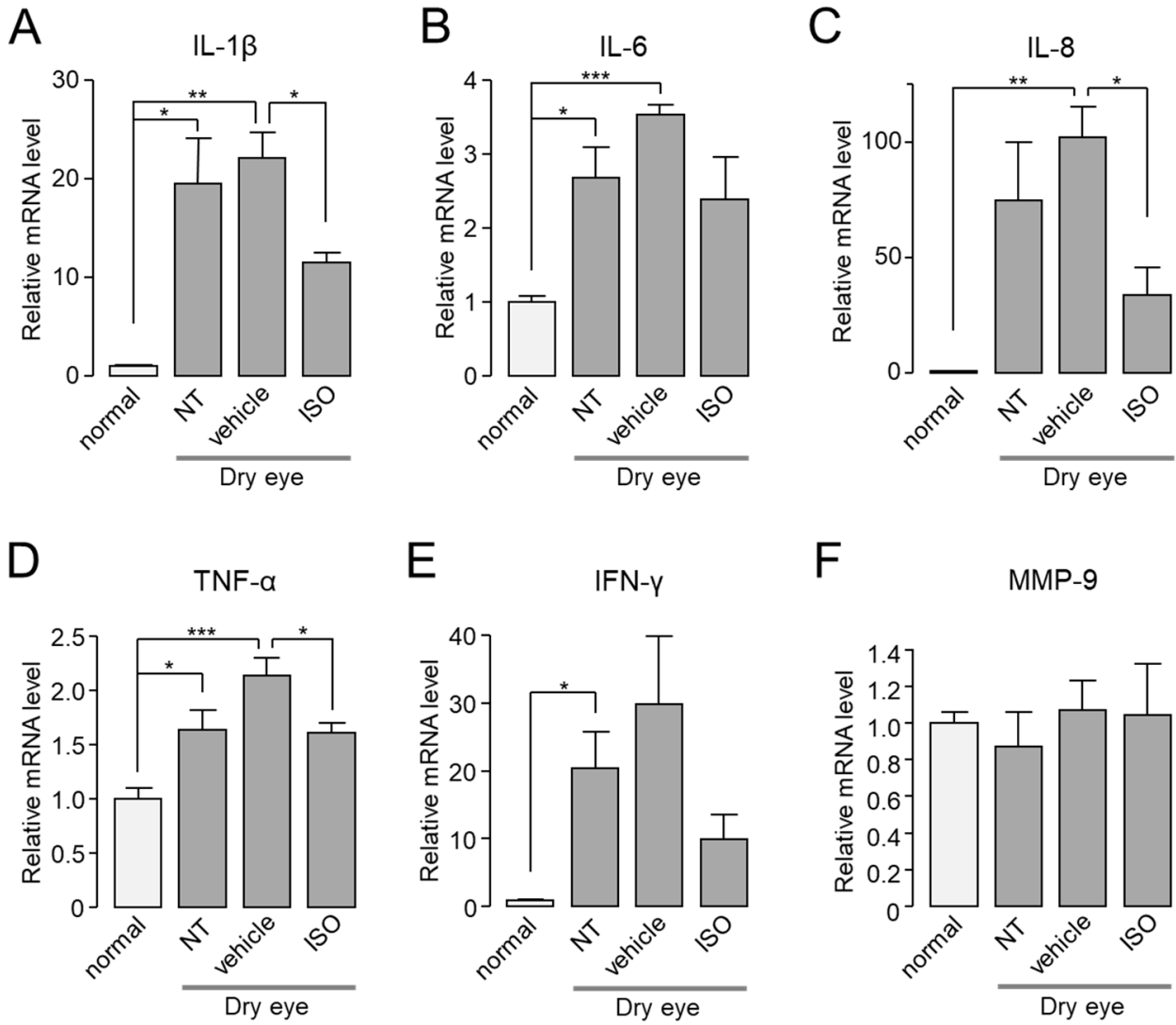

Figure 7. In dry eye mice, isorhamnetin reduced expression of pro-inflammatory cytokines in cornea and conjunctiva. (A-F) The mRNA expression level of IL-1 $\beta$, IL-6, IL-8, TNF- $\alpha$, IFN- $\gamma$, and MMP-9 in cornea and conjunctiva. Mice treated with dry eye model for 14 days, and dry eye mice treated with vehicle or isorhamnetin for 10 days while maintaining the dry eye condition (mean \pm S.E., $n=4-5$ ). NT, not treated. ${ }^{*} p<0.05,{ }^{* *} p<0.01,{ }^{* * *} p<0.001$.

\section{Discussion}

Dry eye disease is a common ocular disease with a variety of symptoms such as discomfort due to inflammation of ocular surface, visual impairment, and increased osmolarity of the tear film [20]. The homeostatic maintenance of lacrimal gland and ocular surface is lost in dry eye, which, in turn, disturbs the balance of the tear film components that stabilize the tear film and protect the ocular surface $[16,21]$. Tear hyperosmolarity is one of the central events in the vicious circle of dry eye, leading to reduced cell volume and increased concentration of solutes. This, in turn, increases expression and production of pro-inflammatory cytokines, chemokines, and matrix metalloproteinase [16].

The inflammatory mediators such as cytokines and nuclear factor-kappa B (NF-kB) have been extensively studied in inflammatory ocular diseases such as uveitis, retinopathy, and macular edema [22-24], and numerous studies on the anti-inflammatory effect of natural flavonoids have been conducted over the past decades [25]. For example, myricetin has a well-established anti-inflammatory role by regulating TNF- $\alpha$-stimulated production of inflammatory mediators by inhibition of NF- $\mathrm{KB}$ pathways [26,27], and quercetin is known for its anti-inflammatory properties primarily via downregulation of NF- $\mathrm{kB}$ both in vitro and in vivo $[28,29]$. To date, several studies have been conducted to investigate the potential use of some flavonoids, such as quercetin, in the prevention or treatment of eye diseases or disorders [30,31].

CFTR is known to be expressed in cornea and conjunctiva and provide an important pathway for fluid secretion across the ocular surface [10,32-34]. CFTR activity was found to be robust in a study of the electrical potential generated by the ocular surface epithelium in human subjects [13]. Thus, enhancement of CFTR $\mathrm{Cl}^{-}$channel activity in the ocular 
epithelium by activators of CFTR can promote secretion of water to the ocular surface in patients with dry eye disease. Interestingly, topical treatment of IBMX, which stimulates CFTR by elevating the intracellular cAMP, on patients with dry eye resulted in an increase in tear secretion and decrease in tear film osmolarity [32]. In addition, patients with CF who have loss-of-function mutations in CFTR have been found to show tear film abnormalities [12,35].

In this study, we found that isorhamnetin is a bona fide activator of CFTR and induces tear secretion via CFTR activation (Figures 3 and 5). Previous studies showed that isorhamnetin, a natural flavonoid, has many biological effects that are applicable to degenerative diseases, such as cardio-cerebrovascular disease, osteoarthritis, and periodontitis [36]. Isorhamnetin can prevent or reduce inflammatory reactions by regulating the activation of different signal pathways such as PI3K/AKT and NF- $\mathrm{KB}[37,38]$. Isorhamnetin also downregulates the secretion of pro-inflammatory cytokines via inhibition of ERK, JNK, and NF- $\mathrm{KB}$ signaling pathway, and its antioxidation and anti-inflammatory effects can be helpful for the treatment of chronic inflammatory diseases that require long-term treatment $[38,39]$. Therefore, the dual beneficial effect of isorhamnetin on dry eye disease is expected through the antioxidant activity and the CFTR activation of the ocular surface epithelium. In addition, there are comorbidities that must be treated together with the underlying dry eye disease, such as recurrent corneal erosions [40]. Since the antioxidant effects of isorhamnetin may be beneficial for other ocular diseases, isorhamnetin should also be tested for therapeutic effects on comorbidities in the future.

Isorhamnetin potently and selectively activated both WT- and $\triangle$ F508-CFTR in a dosedependent manner without increasing intracellular cAMP concentration (Figures 1,2 and 4), and topical treatment of isorhamnetin on ocular surface effectively increased tear volume of normal CD-1 mice for several hours (Figure 5), which showed that efficient tear production and turnover of the tear film could be possible. In a scopolamine-induced dry eye mouse model, the isorhamnetin-treated group exhibited significantly increased tear volumes compared to the vehicle-treated group, and this result correlated with decrease in corneal erosion grade because isorhamnetin improved tear film stability by increasing tear production (Figure 6). Previous clinical studies on inflammatory mediators that occur in dry eye disease have shown elevated levels of IL-1 $\beta$, IL-8, and TNF- $\alpha$ in the tear film of dry eye patients [41,42]. As shown in Figure 7, isorhamnetin significantly reduced these pro-inflammatory cytokines expressed in the cornea of the dry eye mouse model. Isorhamnetin may be a potential agent for the treatment of dry eye caused by lacrimal gland dysfunction in patients with Sjogren's syndrome because it can induce water secretion via CFTR activation in ocular surface epithelium and has anti-inflammatory effect via its antioxidative activity.

Alternative prosecretory therapeutic strategies for dry eye disease that target ion channels on the ocular surface have been investigated. For examples, a $\mathrm{P}_{2} \mathrm{Y}_{2}$ purinergic receptor agonist, diquafosol, promotes both mucin secretion and transient fluid secretion via activation of $\mathrm{Ca}^{2+}$-activated $\mathrm{Cl}^{-}$channels (CaCCs) in ocular surface epithelium [43-45]. Inhibition of ENaC activity by P-301 blocks the absorption of tear and provides driving force for water secretion in ocular surface epithelium [46]. However, a recent study on ion transport of the ocular surface epithelium in human subjects has revealed that $\mathrm{CaCC}$ and $\mathrm{ENaC}$ activities were found to be minimal compared to CFTR [13]. Therefore, CFTR activators, including isorhamnetin, which induce sustained fluid secretion in ocular surface epithelium, may be beneficial in the treatment of patients with dry eye disease.

\section{Materials and Methods}

\subsection{Materials and Reagents}

Isorhamnetin and other chemicals, unless otherwise indicated, were purchased from Sigma-Aldrich (St. Louis, MO, USA). VX-770 was purchased from Selleck Chemicals (Houston, TX, USA). CFTR inh -172 was synthesized as described elsewhere. The compound collections used for screening included 1000 natural products (Spectrum Collection) from 
MicroSource Discovery Inc. (Gaylordsville, CT, USA). Compounds were maintained as dimethyl sulfoxide stock solutions. The $\mathrm{HCO}^{3-}$-buffered solution contained (in $\mathrm{mM}$ ) $120 \mathrm{NaCl}, 5 \mathrm{KCl}, 1 \mathrm{MgCl}_{2}, 1 \mathrm{CaCl}_{2}, 10$ D-glucose, 5 HEPES, and $25 \mathrm{NaHCO}_{3}$ (pH 7.4). In the half- $\mathrm{Cl}^{-}$solution, $65 \mathrm{mM} \mathrm{NaCl}$ in the $\mathrm{HCO}_{3}{ }^{-}$-buffered solution was replaced by $\mathrm{Na}$ gluconate.

\subsection{Cell Culture}

Fisher rat thyroid (FRT) cells expressing human wild-type and $\triangle$ F508-CFTR with a halide sensor YFP-H148Q/I152L were generously provided by Dr. Alan Verkman (University of California, San Francisco, CA, USA) and grown in F-12 Modified Coon's medium supplemented with $10 \%$ FBS, $2 \mathrm{mM}$ glutamine, 100 units $/ \mathrm{mL}$ penicillin, and $100 \mu \mathrm{g} / \mathrm{mL}$ streptomycin. T84 cells were grown in the same medium, generously provided by Dr. Min Goo Lee (Yonsei University, Seoul). CHO-K1 cells expressing human wild-type CFTR with a halide sensor YFP-H148Q/I152L and HEK-293T cells expressing human ether-a-go-gorelated Gene (hERG) were grown in Dulbecco's modified Eagle's medium supplemented with $10 \%$ FBS, $2 \mathrm{mM}$ glutamine, 100 units $/ \mathrm{mL}$ penicillin, and $100 \mu \mathrm{g} / \mathrm{mL}$ streptomycin. Immortalized human corneal epithelial (CorE) cells were grown in bronchial epithelial cell growth medium (Lonza, Switzerland) with all the supplements. Immortalized human conjunctival epithelial (ConjE) cells were grown in corneal epithelial cell medium (ScienCell, CA, USA) with all the supplements.

\subsection{Cell-Based Screening}

CHO cells expressing wild-type CFTR with the halide sensor YFP-H148Q/I152L were plated in 96-well, black-walled microplates (Corning Inc., Corning, NY, USA) at a density of $2 \times 10^{4}$ cells per well. CHO-WT-CFTR-YFP cells were incubated for $48 \mathrm{~h}$ at $37^{\circ} \mathrm{C}$. Assays were done using FLUO star Omega microplate reader (BMG Labtech, Ortenberg, Germany) and MARS Data Analysis Software (BMG Labtech). Briefly, each well of a 96-well plate was washed three times in PBS ( $200 \mu \mathrm{L} /$ wash). Then, $100 \mu \mathrm{L}$ PBS was added to each well. Test compounds $(1 \mu \mathrm{L})$ were added to each well at final concentration of $25 \mu \mathrm{M}$. After $10 \mathrm{~min}, 96$-well plates were transferred to the microplate reader preheated to $37^{\circ} \mathrm{C}$ for fluorescence assay. Each well was assayed individually for CFTR-mediated I- influx by recording fluorescence continuously ( $400 \mathrm{~ms}$ per point) for $2 \mathrm{~s}$ (baseline). Then, $100 \mu \mathrm{L}$ of $140 \mathrm{mM} \mathrm{I}^{-}$solution were added at $2 \mathrm{~s}$ and then YFP fluorescence was recorded for $14 \mathrm{~s}$. Initial iodide influx rate was determined from the initial slope of fluorescence decrease, by nonlinear regression, following infusion of iodide.

\subsection{Short-Circuit Current}

Snapwell inserts containing CFTR-expressing FRT and T84 cells were mounted in Ussing chambers (Physiologic Instruments, San Diego, CA, USA). Forskolin, isorhamnetin, and CFTR $_{\text {inh }}-172$ were added to the apical and basolateral bath solution. For FRT cells, the apical bath was filled with a half- $\mathrm{Cl}^{-}$solution and the basolateral bath was filled with $\mathrm{HCO}^{3-}$-buffered solution to generate transepithelial $\mathrm{Cl}^{-}$gradient (apical, $64 \mathrm{mM}$; basolateral, $129 \mathrm{mM}$ ), and the basolateral membrane was permeabilized with $250 \mu \mathrm{g} / \mathrm{mL}$ amphotericin B. For T84 cells, symmetrical $\mathrm{HCO}^{3-}$-buffered solutions were used, and $\mathrm{ENaC}$ was inhibited with amiloride $(100 \mu \mathrm{M})$. All cells were bathed for a 20-min stabilization period and aerated with $95 \% \mathrm{O}_{2} / 5 \% \mathrm{CO}_{2}$ at $37^{\circ} \mathrm{C}$. Apical membrane current and shortcircuit current were measured with an EVC4000 Multi-Channel V/IClamp (World Precision Instruments, Sarasota, FL, USA) and recorded using PowerLab 4/35 (AD Instruments, Castle Hill, Australia). Data were collected and analyzed with ADInstruments acquisition software Labchart Pro 7 software. The sampling rate was $4 \mathrm{~Hz}$.

\subsection{Patch Clamp}

Whole-cell, patch clamp recordings were performed on CFTR-expressing $\mathrm{CHO}$ cells. The bath solution contained (in mM) 140 NMDG-Cl, $1 \mathrm{CaCl}_{2}, 1 \mathrm{MgCl}_{2}, 10$ glucose, and 
10 HEPES (pH 7.4). The pipette solution contained (in mM) $130 \mathrm{CsCl}$, $0.5 \mathrm{EGTA}, 1 \mathrm{MgCl}_{2}$, 1 Tris-ATP, and 10 HEPES ( $\mathrm{pH}$ 7.2). Pipettes were pulled from borosilicate glass and had resistances of 3-5 M $\Omega$ after fire polishing. Seal resistances were between 3 and $10 \mathrm{G} \Omega$. After establishing the whole-cell configuration, CFTR was activated by forskolin and/or isorhamnetin. Whole-cell currents were elicited by applying hyperpolarizing and depolarizing voltage pulses from a holding potential of $0 \mathrm{mV}$ to potentials between -80 and $+80 \mathrm{mV}$ in steps of $20 \mathrm{mV}$. Recordings were made at room temperature using an Axopatch-200B (Axon Instruments, San Jose, CA, USA). Currents were digitized with a Digidata 1440A converter (Axon Instruments), filtered at $5 \mathrm{kHz}$, and sampled at $1 \mathrm{kHz}$.

\subsection{The cAMP Assay}

FRT cells grown on 96-well culture plates were washed three times with PBS at $37^{\circ} \mathrm{C}$ and then incubated in induction buffer from a cAMP assay kit (cAMP-Glo Assay; Promega, Madison, WI, USA) at $37^{\circ} \mathrm{C}$ containing $100 \mu \mathrm{M}$ 3-isobutyl-1-methylxanthine (IBMX) for $10 \mathrm{~min}$ in the absence or presence of forskolin or isorhamnetin. Cytosolic cAMP was measured using the kit according to the manufacturer's protocol.

\subsection{FluxOR Potassium Ion Channel Assay}

HEK293 cells stably expressing human Kv11.1 (hERG) were plated in 96-well plates. After $48 \mathrm{~h}$, the cells were incubated at $28^{\circ} \mathrm{C}$ for $4 \mathrm{~h}$ to enhance membrane expression of hERG. The culture medium was replaced with $80 \mu \mathrm{L} /$ well of FluxOR (Invitrogen) loading buffer and incubated for $1 \mathrm{~h}$ at $37^{\circ} \mathrm{C}$ in the dark. After removal of the loading buffer, $100 \mu \mathrm{L}$ of assay buffer were added to each well. To measure the effect of isorhamnetin on hERG channels, the cells were pretreated with isorhamnetin for $10 \mathrm{~min}$. FluxOR fluorescence (excitation/emission: $490 / 525 \mathrm{~nm}$ ) was recorded for $4 \mathrm{~s}$ before addition of $20 \mu \mathrm{L}$ of stimulus buffer containing thallium ions, and the fluorescence was monitored. FluxOR fluorescence was recorded and analyzed using FLUOstar Omega Microplate Reader (BMG Labtech) and MARS Data Analysis Software (BMG Labtech). All buffers were prepared according to the manufacturer's instructions.

\subsection{Cell Proliferation Assays}

Immortalized human CorE [47] and immortalized human ConjE (Innoprot, Bizkaia, Spain) cells were plated on 96-well microplates. After $24 \mathrm{~h}$ incubation, cells were treated with $30 \mu \mathrm{M}$ isorhamnetin or $0.01 \%$ Triton X-100 and then they were incubated for two days. An equal amount of DMSO was added to the control. The culture medium and the compounds were changed every $12 \mathrm{~h}$. To assess cell proliferation, after $48 \mathrm{~h}$ of incubation with the compound, the cells were reincubated with MTS for $1 \mathrm{~h}$. The soluble formazan produced by cellular reduction of MTS was quantified by measuring the absorbance at $490 \mathrm{~nm}$ with Infinite M200 (Tecan, Grödig, Austria) microplate reader. MTS assay was done using CellTiter 96 AQueous One Solution Cell Proliferation Assay kit (Promega, Madison, WI, USA).

\subsection{Mouse Ocular Potential Difference (PD) Measurement}

CD-1 mice weighing $30 \mathrm{~g}$ were studied at age 6 weeks. The animal study protocols were approved by the Institutional Animal Ethics Committee of Yonsei University. Transepithelial PDs of the ocular surface were measured continuously in anesthetized mice as described [33]. Mice were anesthetized with 2,2,2-tribromoethanol (avertin, $125 \mathrm{mg} / \mathrm{kg}$ intraperitoneal; Sigma-Aldrich, St. Louis, MO, USA), with additional avertin injected during experiments to maintain anesthesia. Mice were immobilized during the experiment with a custom-built lift, and the face was positioned so that the eye could be faced upward. The eyes were kept hydrated with regular solution that had $\mathrm{NaCl}$ added and matched the mouse blood osmolarity at 320 mOSM flowing out from a perfusion tube connected to a reservoir with the solution in it. The tip of the perfusion tube was positioned $\sim 1 \mathrm{~mm}$ above the ocular surface of the mice. Mice body temperature was kept at $37 \pm 1^{\circ} \mathrm{C}$ by putting 
a heating pad underneath the lift. For measuring the potential difference at the ocular surface, a 1-M KCl agar-bridge connected to an $\mathrm{Ag} / \mathrm{AgCl}$ electrode and high-impedance digital voltmeter (6 1/2 Digits Multimeter; Picotest, Phoenix, AZ, USA) was positioned alongside the tip of the perfusion tube. The reference electrode, which consisted of a second $\mathrm{Ag} / \mathrm{AgCl}$ electrode with 1-M KCl agar-bridge and 320-mOSM, saline-filled syringe needle, was inserted in the subcutaneous tissue at the back. After initial measurement of the baseline, all solutions perfused had $100 \mu \mathrm{M}$ amiloride present. Then $20 \mu \mathrm{M}$ forskolin, $30 \mu \mathrm{M}$ isorhamnetin, and $20 \mu \mathrm{M} \mathrm{CFTR}_{\text {inh }}-172$ were added accordingly to the solution in the reservoir to treat the mouse ocular surface with each respective compound. The potential difference at the mouse ocular surface was recorded using M35XX software (Picotest) at a rate of $250 \mu \mathrm{S}$ per point.

\subsection{Tear Volume}

Tear volume was measured using phenol red threads (Zone-Quick, Oasis Medical, Glendora, CA, USA) by placing them in the lateral canthi of normal CD-1 or dry eye model-treated BL6 mice for $10 \mathrm{~s}$ using forceps. Tear volume was measured using a Vernier caliper as the length of thread wetting under a microscope. For normal CD-1 mice, serial measurements were done to evaluate compound pharmacodynamics compared to the vehicle after topical application of a single, $2.5-\mu \mathrm{L}$ drop of compound formulations containing $20 \mu \mathrm{M}$ forskolin, $30 \mu \mathrm{M}$ isorhamnetin, or $20 \mu \mathrm{M} \mathrm{CFTR}_{\text {inh }}-172$ in PBS with $0.1 \%$ DMSO.

\subsection{Fluorescein Staining}

To assess corneal epithelial disruption, $5 \mu \mathrm{L}$ of fluorescein dye (1\%) were applied to the ocular surface of mice. Photographs of the eye were taken with a digital camera. Each cornea was scored from 0 to 5 according to the Oxford scheme [48].

\subsection{Scopolamine-Induced Dry Eye Mouse Model}

Eight-week-old C57BL/ 6 mice were used for this experiment. Experimental dry eye was induced by subcutaneous injection of $0.5 \mathrm{mg} / 100 \mu \mathrm{L}$ scopolamine hydrobromide (Sigma-Aldrich, St. Louis, MO, USA) three times a day with a standard desiccating environment created by placing the mice in a chamber with a continuous air flow $(15 \mathrm{~L} / \mathrm{min})$ in a room at $25{ }^{\circ} \mathrm{C}$ with an ambient humidity of $12 \%$. Fourteen days after the initiation of experimental dry eye, the mice were treated or not with $5-\mu \mathrm{L}$ drop of ophthalmic formulation $(30 \mu \mathrm{M}$ isorhamnetin in PBS with $0.1 \%$ DMSO) or vehicle three times a day. Eight days after the initiation of the formulation treatment, scopolamine injection was stopped. Ten days after the initiation of the formulation treatment, measurement of tear volume, corneal disruption, and relative mRNA level was performed.

\subsection{Quantitative PCR Analysis}

The mRNA expressions of IL- $1 \beta$, IL- 6 , IL- 8 , TNF- $\alpha$, IFN- $\gamma$, and MMP-9 in cornea and conjunctiva of the dry eye model-treated mice were measured by qPCR. RNA was isolated using TRIzol reagent (Invitrogen, Carlsbad, CA, USA), and $1 \mu \mathrm{g}$ of RNA was used to synthesize complementary DNA (cDNA) using RNA to cDNA EcoDryTM premix (TaKaRa, Shiga, Japan) according to the manufacturer's protocol. The relative mRNA levels were measured in ViiA7 (Applied Biosystems, Foster City, CA, USA) using SYBR Green PCR Master Mix (Applied Biosystems). The primer sequences used were as follows: GAPDH, sense (5-AACGACCCCTTCATTGACCT-3) and antisense (5-ATGTTAGTGGGGTCTCGCTC-3), size of PCR product 155 base pairs; IL-1 $\beta$, sense (5-ACTCATTGTGGCTGTGGAGA-3) and antisense (5-TTGTTCATCTCGGAGCCTGT-3), size of PCR product 199 base pairs; IL-6, sense (5-CTGCAAGAGACTTCCATCCAG-3) and antisense (5-AGTGGTATAGACAGG TCTGTTGG-3), size of PCR product 131 base pairs; IL-8, sense (5-CCCTGTGACACTCAAG AGCT-3) and antisense (5-CAGTAGCCTTCACCCATGGA-3), size of PCR product 190 base pairs; TNF- $\alpha$, sense (5-AGCACAGAAAGCATGATCCG-3) and antisense (5-CGATCACCCC GAAGTTCAGT-3), size of PCR product 166 base pairs; IFN- $\gamma$, sense (5-TTCTTCAGCAACA 
GCAAGGC-3) and antisense (5- ACTCCTTTTCCGCTTCCTGA-3), size of PCR product 156 base pairs; and MMP-9, sense (5-AAAACCTCCAACCTCACGGA-3) and antisense (5-GTGGTGTTCGAATGGCCTTT-3), size of PCR product 190 base pairs. The mRNA levels of the cytokines and MMP-9 were normalized to GAPDH levels and the fold-change in gene expression was determined by using $2^{-\Delta \Delta C T}$ method.

Author Contributions: Conceptualization, H.K.L., I.J., T.-i.K. and W.N.; methodology, H.K.L., J.P. and B.-R.K.; software, H.K.L.; validation, H.K.L., J.P. and B.-R.K.; formal analysis, H.K.L.; investigation, H.K.L. and W.N.; resources, W.N.; data curation, H.K.L. and W.N.; writing-original draft preparation, H.K.L.; writing—review and editing, W.N.; supervision, W.N.; project administration, H.K.L.; funding acquisition, J.P. and WN. All authors have read and agreed to the published version of the manuscript.

Funding: This research was supported by a Basic Science Research Program through the National Research Foundation of Korea (NRF) funded by the Ministry of Education NRF (2015R1D1A1A01057695 and 2018R1A6A1A03023718) to Wan Namkung, and NRF (2017R1A6A3A11031453 and 2020R1C1C100 8332) to Jinhong Park.

Conflicts of Interest: All the authors declared no competing interests.

$\begin{array}{ll}\text { Abbreviations } \\ \text { CFTR } & \begin{array}{l}\text { cystic fibrosis transmembrane conductance regulator } \\ \text { anoctamin-1 }\end{array} \\ \text { ANO1 } & \begin{array}{l}\text { transmembrane member 16A } \\ \text { TMEM16A }\end{array} \\ \text { TNF- } \alpha & \text { tumor necrosis factor- } \alpha \\ \text { IL } & \text { interleukin } \\ \text { IFN- } \gamma & \text { interferon- } \gamma \\ \text { ENaC } & \text { epithelial sodium channel } \\ \text { cAMP } & \text { cyclic adenosine monophosphate } \\ \text { FRT } & \text { fisher rat thyroid } \\ \text { CorE } & \text { corneal epithelial } \\ \text { ConjE } & \text { conjunctival epithelial } \\ \text { PD } & \text { potential difference } \\ \text { NF- } \text { B } & \text { nuclear factor } \kappa \text { B } \\ \text { hERG } & \text { human ether-a-go-go-related Gene } \\ \text { MMP-9 } & \text { matrix metallopeptidase } 9\end{array}$

\section{References}

1. O'Brien, P.D.; Collum, L.M. Dry eye: Diagnosis and current treatment strategies. Curr. Allergy Asthma Rep. $2004,4,314-319$. [CrossRef]

2. Miljanovic, B.; Dana, R.; Sullivan, D.A.; Schaumberg, D.A. Impact of dry eye syndrome on vision-related quality of life. Am. J. Ophthalmol. 2007, 143, 409-415. [CrossRef] [PubMed]

3. Uchino, M.; Schaumberg, D.A. Dry Eye Disease: Impact on Quality of Life and Vision. Curr. Ophthalmol. Rep. 2013, 1, 51-57. [CrossRef] [PubMed]

4. Shah, S.; Jani, H. Prevalence and associated factors of dry eye: Our experience in patients above 40 years of age at a Tertiary Care Center. Oman J. Ophthalmol. 2015, 8, 151-156. [CrossRef] [PubMed]

5. Yamaguchi, T. Inflammatory Response in Dry Eye. Investig. Opthalmol. Vis. Sci. 2018, 59, DES192-DES199. [CrossRef]

6. Tatlipinar, S.; Akpek, E.K. Topical ciclosporin in the treatment of ocular surface disorders. Br. J. Ophthalmol. 2005, 89, 1363-1367. [CrossRef]

7. Pucker, A.D.; Ng, S.M.; Nichols, J.J. Over the counter (OTC) artificial tear drops for dry eye syndrome. Cochrane Database Syst. Rev. 2016, 2, Cd009729. [CrossRef]

8. Lau, O.C.; Samarawickrama, C.; Skalicky, S.E. P2Y2 receptor agonists for the treatment of dry eye disease: A review. Clin. Ophthalmol. 2014, 8, 327-334. [CrossRef]

9. Itoh, R.; Kawamoto, S.; Miyamoto, Y.; Kinoshita, S.; Okubo, K. Isolation and characterization of a Ca(2+)-activated chloride channel from human corneal epithelium. Curr. Eye Res. 2000, 21, 918-925. [CrossRef]

10. Turner, H.C.; Bernstein, A.; Candia, O.A. Presence of CFTR in the conjunctival epithelium. Curr. Eye Res. 2002, $24,182-187$. [CrossRef]

11. Yu, D.; Thelin, W.R.; Rogers, T.D.; Stutts, M.J.; Randell, S.H.; Grubb, B.R.; Boucher, R.C. Regional differences in rat conjunctival ion transport activities. Am. J. Physiol. Cell Physiol. 2012, 303, C767-C780. [CrossRef] [PubMed] 
12. Mrugacz, M.; Minorowska, A.; Bakunowicz-Lazarczyk, A.; Zywalewska, N. Dry eye syndrome in children with cystic fibrosis. Med. Wieku Rozw. 2004, 8, 865-870.

13. Pasricha, N.D.; Smith, A.J.; Levin, M.H.; Schallhorn, J.M.; Verkman, A.S. Ocular Surface Potential Difference Measured in Human Subjects to Study Ocular Surface Ion Transport. Transl. Vis. Sci. Technol. 2020, 9, 20. [CrossRef] [PubMed]

14. Lee, S.; Phuan, P.W.; Felix, C.M.; Tan, J.A.; Levin, M.H.; Verkman, A.S. Nanomolar-Potency Aminophenyl-1,3,5-triazine Activators of the Cystic Fibrosis Transmembrane Conductance Regulator (CFTR) Chloride Channel for Prosecretory Therapy of Dry Eye Diseases. J. Med. Chem. 2017, 60, 1210-1218. [CrossRef] [PubMed]

15. Ostedgaard, L.S.; Rogers, C.S.; Dong, Q.; Randak, C.O.; Vermeer, D.W.; Rokhlina, T.; Karp, P.H.; Welsh, M.J. Processing and function of CFTR-DeltaF508 are species-dependent. Proc. Natl. Acad. Sci. USA 2007, 104, 15370-15375. [CrossRef] [PubMed]

16. Massingale, M.L.; Li, X.; Vallabhajosyula, M.; Chen, D.; Wei, Y.; Asbell, P.A. Analysis of inflammatory cytokines in the tears of dry eye patients. Cornea 2009, 28, 1023-1027. [CrossRef] [PubMed]

17. Bron, A.J.; de Paiva, C.S.; Chauhan, S.K.; Bonini, S.; Gabison, E.E.; Jain, S.; Knop, E.; Markoulli, M.; Ogawa, Y.; Perez, V.; et al. TFOS DEWS II pathophysiology report. Ocul. Surf. 2017, 15, 438-510. [CrossRef]

18. Pflugfelder, S.C.; De Paiva, C.S.; Moore, Q.L.; Volpe, E.A.; Li, D.Q.; Gumus, K.; Zaheer, M.L.; Corrales, R.M. Aqueous Tear Deficiency Increases Conjunctival Interferon- $\gamma($ IFN- $\gamma)$ Expression and Goblet Cell Loss. Investig. Opthalmol. Vis. Sci. 2015, 56, 7545-7550. [CrossRef] [PubMed]

19. Lanza, N.L.; Valenzuela, F.; Perez, V.L.; Galor, A. The Matrix Metalloproteinase 9 Point-of-Care Test in Dry Eye. Ocul. Surf. 2016, 14, 189-195. [CrossRef]

20. The definition and classification of dry eye disease: Report of the Definition and Classification Subcommittee of the International Dry Eye WorkShop (2007). Ocul. Surf. 2007, 5, 75-92. [CrossRef]

21. Stern, M.E.; Schaumburg, C.S.; Dana, R.; Calonge, M.; Niederkorn, J.Y.; Pflugfelder, S.C. Autoimmunity at the ocular surface: Pathogenesis and regulation. Mucosal Immunol. 2010, 3, 425-442. [CrossRef]

22. Ooi, K.G.; Galatowicz, G.; Calder, V.L.; Lightman, S.L. Cytokines and chemokines in uveitis: Is there a correlation with clinical phenotype? Clin. Med. Res. 2006, 4, 294-309. [CrossRef]

23. Zhou, J.; Wang, S.; Xia, X. Role of intravitreal inflammatory cytokines and angiogenic factors in proliferative diabetic retinopathy. Curr. Eye Res. 2012, 37, 416-420. [CrossRef] [PubMed]

24. Sonoda, S.; Sakamoto, T.; Yamashita, T.; Shirasawa, M.; Otsuka, H.; Sonoda, Y. Retinal morphologic changes and concentrations of cytokines in eyes with diabetic macular edema. Retina 2014, 34, 741-748. [CrossRef]

25. Azab, A.; Nassar, A.; Azab, A.N. Anti-Inflammatory Activity of Natural Products. Molecules 2016, 21, 1321. [CrossRef] [PubMed]

26. Lee, D.H.; Lee, C.S. Flavonoid myricetin inhibits TNF- $\alpha$-stimulated production of inflammatory mediators by suppressing the Akt, mTOR and NF-kB pathways in human keratinocytes. Eur. J. Pharmacol. 2016, 784, 164-172. [CrossRef] [PubMed]

27. Park, H.H.; Lee, S.; Son, H.Y.; Park, S.B.; Kim, M.S.; Choi, E.J.; Singh, T.S.; Ha, J.H.; Lee, M.G.; Kim, J.E.; et al. Flavonoids inhibit histamine release and expression of proinflammatory cytokines in mast cells. Arch. Pharm. Res. 2008, 31, 1303-1311. [CrossRef] [PubMed]

28. Min, Y.D.; Choi, C.H.; Bark, H.; Son, H.Y.; Park, H.H.; Lee, S.; Park, J.W.; Park, E.K.; Shin, H.I.; Kim, S.H. Quercetin inhibits expression of inflammatory cytokines through attenuation of NF-kappaB and p38 MAPK in HMC-1 human mast cell line. Inflamm. Res. 2007, 56, 210-215. [CrossRef]

29. Rogerio, A.P.; Kanashiro, A.; Fontanari, C.; da Silva, E.V.; Lucisano-Valim, Y.M.; Soares, E.G.; Faccioli, L.H. Anti-inflammatory activity of quercetin and isoquercitrin in experimental murine allergic asthma. Inflamm. Res. 2007, 56, 402-408. [CrossRef]

30. Majumdar, S.; Srirangam, R. Potential of the bioflavonoids in the prevention/treatment of ocular disorders. J. Pharm. Pharmacol. 2010, 62, 951-965. [CrossRef] [PubMed]

31. Oh, H.N.; Kim, C.E.; Lee, J.H.; Yang, J.W. Effects of Quercetin in a Mouse Model of Experimental Dry Eye. Cornea 2015, 34, 1130-1136. [CrossRef]

32. Gilbard, J.P.; Rossi, S.R.; Heyda, K.G.; Dartt, D.A. Stimulation of tear secretion and treatment of dry-eye disease with 3-isobutyl-1methylxanthine. Arch. Ophthalmol. 1991, 109, 672-676. [CrossRef] [PubMed]

33. Levin, M.H.; Verkman, A.S. CFTR-regulated chloride transport at the ocular surface in living mice measured by potential differences. Investig. Opthalmol. Vis. Sci. 2005, 46, 1428-1434. [CrossRef] [PubMed]

34. Shiue, M.H.; Gukasyan, H.J.; Kim, K.J.; Loo, D.D.; Lee, V.H. Characterization of cyclic AMP-regulated chloride conductance in the pigmented rabbit conjunctival epithelial cells. Can. J. Physiol. Pharmacol. 2002, 80, 533-540. [CrossRef] [PubMed]

35. Morkeberg, J.C.; Edmund, C.; Prause, J.U.; Lanng, S.; Koch, C.; Michaelsen, K.F. Ocular findings in cystic fibrosis patients receiving vitamin A supplementation. Graefe's Arch. Clin. Exp. Ophthalmol. 1995, 233, 709-713. [CrossRef]

36. Gong, G.; Guan, Y.Y.; Zhang, Z.L.; Rahman, K.; Wang, S.J.; Zhou, S.; Luan, X.; Zhang, H. Isorhamnetin: A review of pharmacological effects. Biomed. Pharmacother. 2020, 128, 110301. [CrossRef] [PubMed]

37. Kim, S.Y.; Jin, C.Y.; Kim, C.H.; Yoo, Y.H.; Choi, S.H.; Kim, G.Y.; Yoon, H.M.; Park, H.T.; Choi, Y.H. Isorhamnetin alleviates lipopolysaccharide-induced inflammatory responses in BV2 microglia by inactivating NF- $\mathrm{B}$, blocking the TLR4 pathway and reducing ROS generation. Int. J. Mol. Med. 2019, 43, 682-692. [CrossRef]

38. Li, Y.; Chi, G.; Shen, B.; Tian, Y.; Feng, H. Isorhamnetin ameliorates LPS-induced inflammatory response through downregulation of NF-KB signaling. Inflammation 2016, 39, 1291-1301. [CrossRef] [PubMed] 
39. Chi, G.; Zhong, W.; Liu, Y.; Lu, G.; Lü, H.; Wang, D.; Sun, F. Isorhamnetin protects mice from lipopolysaccharide-induced acute lung injury via the inhibition of inflammatory responses. Inflamm. Res. 2016, 65, 33-41. [CrossRef] [PubMed]

40. Napoli, P.E.; Braghiroli, M.; Iovino, C.; Demarinis, G.; Fossarello, M. A study of refractory cases of persistent epithelial defects associated with dry eye syndrome and recurrent corneal erosions successfully treated with cyclosporine A $0.05 \%$ eye drops. Drug Des. Dev. Ther. 2019, 13, 2001-2008. [CrossRef] [PubMed]

41. Solomon, A.; Dursun, D.; Liu, Z.; Xie, Y.; Macri, A.; Pflugfelder, S.C. Pro- and anti-inflammatory forms of interleukin-1 in the tear fluid and conjunctiva of patients with dry-eye disease. Investig. Ophthalmol. Vis. Sci. 2001, 42, 2283-2292.

42. Yoon, K.C.; Jeong, I.Y.; Park, Y.G.; Yang, S.Y. Interleukin-6 and tumor necrosis factor-alpha levels in tears of patients with dry eye syndrome. Cornea 2007, 26, 431-437. [CrossRef]

43. Pendergast, W.; Yerxa, B.R.; Douglass, J.G., 3rd; Shaver, S.R.; Dougherty, R.W.; Redick, C.C.; Sims, I.F.; Rideout, J.L. Synthesis and P2Y receptor activity of a series of uridine dinucleoside 5'-polyphosphates. Bioorg. Med. Chem. Lett. 2001, 11, 157-160. [CrossRef]

44. Fujihara, T.; Murakami, T.; Fujita, H.; Nakamura, M.; Nakata, K. Improvement of corneal barrier function by the P2Y(2) agonist INS365 in a rat dry eye model. Investig. Ophthalmol. Vis. Sci. 2001, 42, 96-100.

45. Fujihara, T.; Murakami, T.; Nagano, T.; Nakamura, M.; Nakata, K. INS365 suppresses loss of corneal epithelial integrity by secretion of mucin-like glycoprotein in a rabbit short-term dry eye model. J. Ocul. Pharmacol. Ther. 2002, 18, 363-370. [CrossRef] [PubMed]

46. Thelin, W.R.; Johnson, M.R.; Hirsh, A.J.; Kublin, C.L.; Zoukhri, D. Effect of topically applied epithelial sodium channel inhibitors on tear production in normal mice and in mice with induced aqueous tear deficiency. J. Ocul. Pharmacol. Ther. 2012, 28, 433-438. [CrossRef]

47. Gipson, I.K.; Spurr-Michaud, S.; Argüeso, P.; Tisdale, A.; Ng, T.F.; Russo, C.L. Mucin gene expression in immortalized human corneal-limbal and conjunctival epithelial cell lines. Opthalmol. Vis. Sci. 2003, 44, 2496-2506. [CrossRef]

48. Bang, S.P.; Yeon, C.Y.; Adhikari, N.; Neupane, S.; Kim, H.; Lee, D.C.; Son, M.J.; Lee, H.G.; Kim, J.Y.; Jun, J.H. Cyclosporine A eyedrops with self-nanoemulsifying drug delivery systems have improved physicochemical properties and efficacy against dry eye disease in a murine dry eye model. PLoS ONE 2019, 14, e0224805. [CrossRef] 